\title{
Utilization of Low Sulfur Fly Ash from Circulating Fluidized Bed Combustion Burner as Geopolymer Binder
}

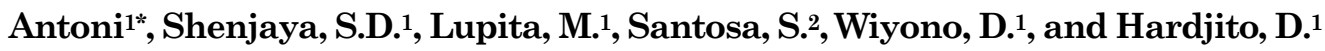

\begin{abstract}
Circulating fluidized bed combustion (CFBC) burner is gaining increasing popularity due to its compact size, high efficiency, and lower burning temperature compared with the pulverized coal combustion (PCC) burner. Normally, fly ash produced from CFBC burner is not rounded, requires higher water content, and has high sulfur content. Due to its drawbacks, CFBC fly ash is rarely used as cementitious material or geopolymer precursor. This study focuses on comparing variations in the concentration of $\mathrm{NaOH}$ solution and in the ratio of alkaline activators to the properties of low sulfur CFBC fly ash-based geopolymer mortars. It was concluded that the fly ash has the potential to be utilized as a geopolymer precursor although with an increase in water demand. The geopolymer mortar shows good compressive strength and stability. The highest compressive strength of $33.4 \mathrm{MPa}$ at 90 days was achieved at $\mathrm{NaOH}$ concentration of $8 \mathrm{M}$ and ratio of sodium silicate solution to sodium hydroxide solution of 2.5 with excellent stability.
\end{abstract}

Keywords: Fly ash; fluidized bed; CFBC; workability; compressive strength.

\section{Introduction}

Geopolymer is an alternative cementitious material synthesized by combining alumino-silicates material with strong alkali activator solution. Fly ash, which is rich in alumina and silicates, is the waste of coal combustion and has been used extensively as a precursor in making geopolymer [1]. Fly ash is a residue from the coal-burning process that was captured before the gas flue was opened into the atmosphere. Based on the combustion system, there are two popular systems: pulverized coal combustion (PCC) and fluidized bed combustion (FBC) [2]. The PCC process uses a temperature of $1300-1700^{\circ} \mathrm{C}$ and produces spherical fly ash with a particle size of $1-200$ $\mu \mathrm{m}$. In contrast, the FBC process uses a temperature of $800-900^{\circ} \mathrm{C}$, generating fly ash particle sizes of $1-$ $300 \mu \mathrm{m}$. Based on its fluidization level, the FBC combustion system is divided into two types: the bubbling bed unit and the circulating unit (CFBC) [3] . The use of circulating flue gas in the CFBC burner also improves its efficiency as most of the unburned coal is circulated back into the burner chamber for another round of burning, producing a consistent, very low-carbon ash.

${ }^{1}$ Civil Engineering Department, Faculty of Civil Engineering and Planning, Petra Christian University, Jl. Siwalankerto 121-131, Surabaya 60236, INDONESIA

${ }^{2}$ Doctoral Student in Civil Engineering Department, Faculty of Civil Engineering and Planning, Petra Christian University, J. Siwalankerto 121-131, Surabaya 60236, INDONESIA

*Corresponding author; Email: antoni@petra.ac.id

Note: Discussion is expected before November, $1^{\text {st }} 2020$, and will be published in the "Civil Engineering Dimension", volume 23, number 1, March 2021.

Received 12 August 2020; revised 28 September 2020; accepted 29 September 2020.
The main advantage of FBC is that it uses calcium carbonate injection to absorb sulfur and, thus, reduces the emission of sulfur oxide gases. However, the content of $\mathrm{CaO}$ and $\mathrm{SO}_{3}$ in the fly ash from the $\mathrm{FBC}$ system is much more than the PCC system; therefore, its use as a pozzolanic material is limited [4]. Until now, the more commonly used fly ash for making concrete has been PCC fly ash due to its round shape, lower water use, and high reactivity [5]. In comparison, CFBC fly ash is very rarely used in concrete, mainly due to the high sulfur content and irregular shape (increased surface area) that cause difficulties when mixed in concrete [6].

A previous study using a mixture of FBC fly ash with PCC fly ash as a geopolymer material showed that the compressive strength of geopolymer mortar at seven days was lower if the percentage of FBC fly ash usage was higher than PCC fly ash [7]. Another study using CFBC fly ash type $\mathrm{C}$ as a geopolymer material produced paste with the highest compressive strength yield of $6.5 \mathrm{MPa}$ at seven days [8]. The result of the compressive strength test is quite low; therefore, the composition proposed cannot be adopted. The low strength could be due to the physical nature of the CFBC fly ash that required higher free water in the mixture as well as the high sulfur content in its chemical composition that causes an unwanted reaction. The CFBC fly ash has a high $\mathrm{CaO}$ and $\mathrm{SO}_{3}$ content that causes an unwanted reaction with the alkaline activator, and can only be used in conjunction with the PCC fly ash at a low replacement ratio [7]. An effort to improve the workability of CFBC fly ash also has been conducted by grinding the fly ash to obtain a finer particle size. However, the stability of the geopolymer matrix obtained was still unclear [9]. 
This study explores the use of fly ash from a CFBC power plant, in Ngoro, East Java, Indonesia, as a base material for geopolymer mortar. The fly ash was found to have a low sulfur content because no calcium carbonate was injected into the burner. The study aimed to analyze the variation of alkaline activator (concentration of $\mathrm{NaOH}$ solution and the ratio of sodium silicate solution and $\mathrm{NaOH}$ solution) to produce the optimum compressive strength of geopolymer mortar. As shown previously, the ratio of alkaline activator has very high significance in the reaction of the geopolymer matrix $[1,10,11]$. The stability of the resulting reaction was investigated by capillary test to observe the potential of efflorescence in the geopolymer mortar $[12,13]$. The prospects and challenges in using CFBC fly ash as the precursor of geopolymer concrete are also presented in this paper.

\section{Experimental Procedure}

\section{Material and Mix Proportion}

Materials used in this study were CFBC fly ash, fine aggregate, alkaline activator, and mineral water as a primary material for geopolymer paste and mortar. Fly ash was obtained from the Ngoro Power Plant, Mojokerto, East Java, Indonesia, which uses CFBC burner system. In this plant, 650 tons of coal are burned to produce about 40 tons of fly ash every day. Currently, fly ash produced from this power plant is classified as raw material grade for cement production, because it does not comply with the requirements as supplementary material for cement. Fly ash was collected at two sampling periods (NA and NB) to show the variability of the fly ash. The fine aggregate used was in the form of silica sand from Tuban, East Java, Indonesia. Silica sand was prepared in saturated-surface dry condition.

Alkaline activator used is a mixture of $\mathrm{NaOH}$ solution and sodium silicate solution. $\mathrm{NaOH}$ solution was prepared by mixing $\mathrm{NaOH}$ pellets and water. Mixing the solid $\mathrm{NaOH}$ with water is an exothermic reaction. Therefore, $\mathrm{NaOH}$ solution was allowed to stand for 24 hours before casting. The sodium silicate solution used contains $16.10 \% \mathrm{Na}_{2} \mathrm{O}, 37.84 \% \mathrm{SiO}_{2}$, and $46.06 \%$ water.

Geopolymer paste and mortar were made with alkaline activator varied for the concentration of $\mathrm{NaOH}$ solution $(6 \mathrm{M}, 8 \mathrm{M}, 10 \mathrm{M}$, and $12 \mathrm{M})$ and for the ratio of sodium silicate solution and $\mathrm{NaOH}$ solution (SS/NS) (3.0, 2.5, 2.0, 1.0, and 0.5). The $\mathrm{NaOH}$ concentration of $12 \mathrm{M}$ was only used in mixtures with $\mathrm{SS} / \mathrm{NS}$ of 2.5 and 1.0. The ratio of fly ash and sand was fixed at 0.5 by mass. The water to binder ratio used in this study was 0.375 for NA fly ash and 0.55 for fly ash NB, determined after performing the normal consistency test. NA fly ash was tested for all properties, whereas NB fly ash was only tested for its compressive strength with $\mathrm{NaOH}$ solutions of $6 \mathrm{M}, 8$ $\mathrm{M}, 10 \mathrm{M}$, and $12 \mathrm{M}$ and with SS/NS of 1 and 2.5.

\section{Specimen Preparation and Testing}

The equipments used were conic rings for the Vicat test, Vicat needles (1 $\mathrm{mm}$ and $10 \mathrm{~mm}$ diameter) to measure setting time and normal consistency, $5 \mathrm{~cm}$ cube steel mold, plastic cylinder mold with diameter 6 $\mathrm{cm}$ and height $12 \mathrm{~cm}$, vibrating table, curing oven, measuring cups, digital scales, and a drill as mixing equipment. The cube mold was used to cast the geopolymer mortar for compressive strength testing and the cylinder plastic mold was used to cast the geopolymer mortar to observe its efflorescence potential.

A normal consistency test on fly ash was used to measure its water demand according to ASTM C187 [14]. The setting time test was carried out on geopolymer paste using the Vicat apparatus. Setting time data were measured at ambient temperature for the initial and final sets, following ASTM C 191 [15]. The time elapsed between the initial contact of cement and water when the Vicat needle penetration is at $25 \mathrm{~mm}$ is taken as the initial set. The time elapsed between initial contact of cement and water when the needle does not leave a complete circular impression in the paste surface is taken as the final set.

The preparation of geopolymer paste began with mixing the $\mathrm{NaOH}$ solution first and then allowed it to stand for 24 hours before mixing it with the sodium silicate solution to make an alkaline activator solution. After that, the alkaline activator was mixed with fly ash and stirred evenly. Then, the geopolymer paste was poured into the conic ring to test its setting time at room temperature.

The initial procedure for making geopolymer mortar was the same as the procedure for making geopolymer paste. After the alkaline activator was mixed with fly ash and was stirred evenly, the paste mixture was mixed with sand and stirred evenly. The workability test for the mortar mixture followed the ASTM flow table test [16]. The mortar was placed on the mold and the table was dropped 25 times in 15 second, then the diameter of the mortar was measured and averaged in two directions. The wider the flow diameter the better the flowability because segregation does not occur.

Before the geopolymer mortar mixture was poured into the formwork, cooking oil was applied to the formwork as a release agent. The geopolymer mortar mixture was poured into the $5 \mathrm{~cm}$ cube formwork and $6 \times 12 \mathrm{~cm}$ plastic tubes and then vibrated at the vibrating table. The mortar specimens were then 
wrapped in plastic sheet and cured in an oven at $60^{\circ} \mathrm{C}$ for 24 hours. The compressive strength of the mortar was tested at 7, 28, and 90 days. Visual inspection was also conducted on the geopolymer mortar by immersing the specimen in a $1 \mathrm{~cm}$ of water for 28 days to evaluate the possible occurrence of efflorescence. If the geopolymer matrix was unstable, then the mortar would exhibit efflorescence on the surface, indicating an incomplete geopolymer reaction.

\section{Results and Discussion}

\section{Properties of the Fly Ash}

The fly ash was tested to investigate its physical and chemical properties, i.e., acidity $(\mathrm{pH})$, specific gravity, normal consistency, particle size distribution, X-ray fluorescence (XRF), X-ray diffraction (XRD), and scanning electron microscope (SEM) imagery. The $\mathrm{pH}$ test on the fly ash was carried out based on ASTM D 5239 [17]. The physical and chemical properties of the fly ash are shown in Table 1 and Table 2 , respectively. The fly ash could be categorized as class $\mathrm{F}$ fly ash because the total amount of $\mathrm{SiO}_{2}+\mathrm{Al}_{2} \mathrm{O}_{3}+\mathrm{Fe}_{2} \mathrm{O}_{3}$ is $90 \%$, which is more than the $70 \%$ specified in ASTM C618. The $\mathrm{SO}_{3}$ content is also well below 5\%. This result shows that the sulfur content in the CFBC fly ash used in this study is very low compared with those obtained when calcium carbonate was injected into the burner $[18,19]$. The difference in chemical properties would cause different geopolymer product.

CFBC fly ash has a unique characteristic in that the water demand is quite high compared with PCC fly ash. Therefore, it is essential to measure the normal consistency for each fly ash sample. The two fly ash samples obtained in this study showed a wide range of normal consistency. The particle size analysis showed that the fly ash size was similar to other cementitious materials with very high surface area.

XRD testing was carried out to characterize the crystalline structure and crystal size of a solid material. Figure 1 shows the XRD result for NA and NB fly ash. The peaks between the two samples of fly ash have almost the same shape, showing the similar reactivity potential of the NA and NB fly ash. In addition, the result shows that the fly ash was mostly in amorphous phase, besides the presence of some quartz and hematite crystal.

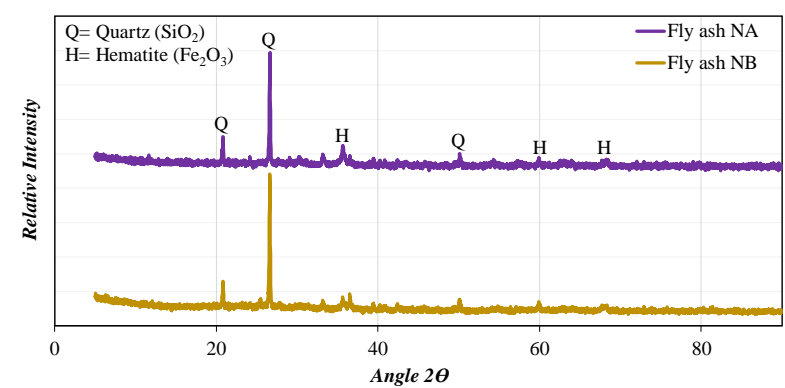

Figure 1. XRD Result for the NA and NB Fly Ash.
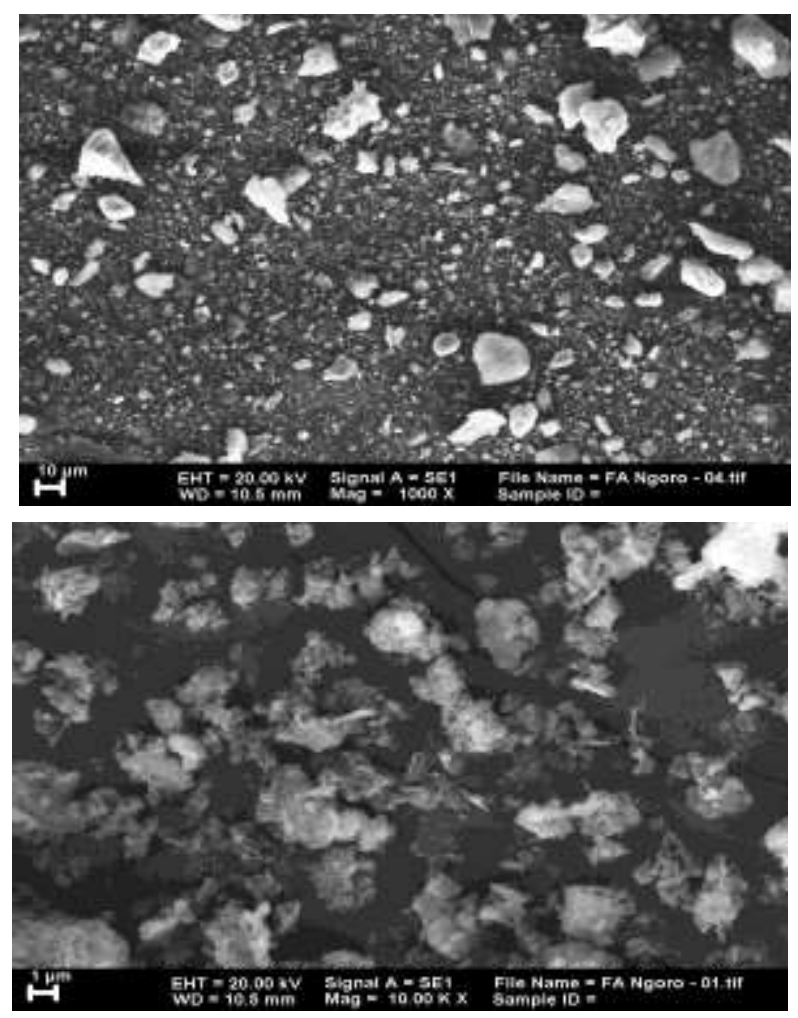

Figure 2. Scanning Electron Microscope Images of the NB Fly Ash at $1000 \times$ (above) and 10,000× (below) Magnification.

The physical appearance of the fly ash was observed in images obtained by the scanning electron microscope and presented as Figure 2. The CFBC fly ash was not rounded as typical properties resulted from the higher combustion temperature in the PCC burner. At 10,000× magnification, the fly ash shape was shown to be highly irregular with many porous particles. The physical shape and mineralogy of the ash produced in the CFBC burner have been

Table 1. Properties of the Fly Ash used in this Research

\begin{tabular}{cccccccc}
\hline Fly Ash & Specific Gravity & $\mathrm{pH}$ & $\begin{array}{c}\text { Normal consistency } \\
(\mathrm{w} / \mathrm{b})\end{array}$ & $\begin{array}{c}\mathrm{d}(10) \\
(\mu \mathrm{m})\end{array}$ & $\begin{array}{c}\mathrm{d}(50) \\
(\mu \mathrm{m})\end{array}$ & $\begin{array}{c}\mathrm{d}(90) \\
(\mu \mathrm{m})\end{array}$ & $\begin{array}{c}\text { SSA } \\
\left(\mathrm{cm}^{2} / \mathrm{g}\right)\end{array}$ \\
\hline NA & 2.211 & 9.3 & 0.375 & 0.72 & 24.67 & 92.64 & 19477.23 \\
$\mathrm{NB}$ & 2.375 & 5.9 & 0.55 & 1.52 & 29.37 & 84.26 & 7637.97 \\
\hline
\end{tabular}

Table 2. Chemical Compounds of the NB Fly Ash from the XRF Test

\begin{tabular}{ccccccccccccc}
\hline Compound & $\mathrm{SiO}_{2}$ & $\mathrm{Al}_{2} \mathrm{O}_{3}$ & $\mathrm{Fe}_{2} \mathrm{O}_{3}$ & $\mathrm{TiO}_{2}$ & $\mathrm{CaO}$ & $\mathrm{MgO}$ & $\mathrm{K}_{2} \mathrm{O}$ & $\mathrm{Na}_{2} \mathrm{O}$ & $\mathrm{SO}_{3}$ & $\mathrm{MnO}_{2}$ & $\mathrm{P}_{2} \mathrm{O}_{5}$ & $\mathrm{LoI}$ \\
\hline \% mass & 48.9 & 35.1 & 5.99 & 1.93 & 2.2 & 1.34 & 0.95 & 0.4 & 0.15 & 0.07 & 0.14 & 2.5 \\
\hline
\end{tabular}


discussed in depth by Silva et al. [20]. The porous nature of the CFBC ash could be the reason for the higher water content required to make a workable mixture.

\section{Setting Time}

The setting time of the geopolymer paste was tested for NA fly ash at room temperature. The initial and final setting times of the geopolymer paste at various alkaline activator ratios and concentrations are shown in Figure 3.

The fastest initial setting time and final setting time were found for geopolymer paste with a ratio of sodium silicate solution and $\mathrm{NaOH}$ solution (SS/NS) of 1.0 at $8 \mathrm{M} \mathrm{NaOH}$ solution, with a duration of 190 minutes and 342 minutes, respectively. The longest initial setting time was found for $\mathrm{SS} / \mathrm{NS}=2.5$ and 12 $\mathrm{M} \mathrm{NaOH}$ solution. Meanwhile, the longest final setting time was 1575 minutes, occurs on geopolymer matrix with $\mathrm{SS} / \mathrm{NS}=0.5$ and $10 \mathrm{M} \mathrm{NaOH}$ solution. Geopolymer paste with $\mathrm{NaOH}$ concentrations of $6 \mathrm{M}$, $8 \mathrm{M}$, and $10 \mathrm{M}$ had the fastest time to reach the initial setting and final setting times for its proportion, showing that the reactivity of the fly ash was at its optimum condition.

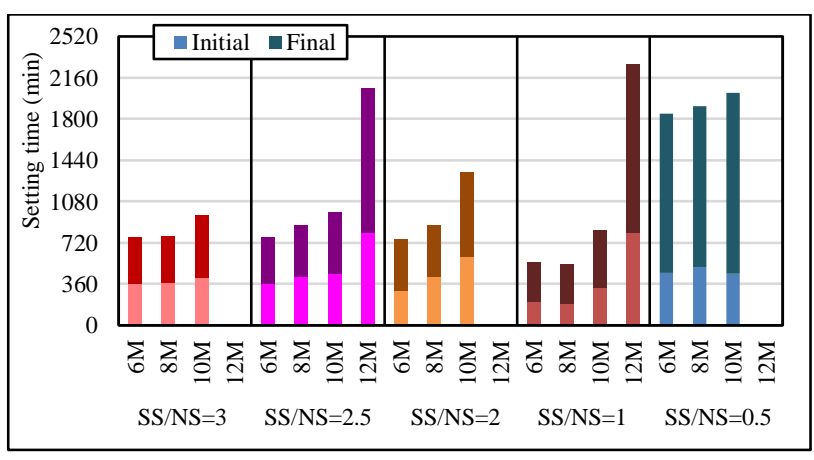

Figure 3. Setting Time of Geopolymer Paste with Variations of $\mathrm{NaOH}$ Concentration and Sodium Silicate Solution to Sodium Hydroxide Solution Ratio (SS/NS) for NA Fly Ash.

Faster setting time of the paste is an indicator of the high reaction rate of the fly ash. It should be noted that setting time tests were carried out at room temperature. Therefore, the mixture must run its own reaction without any acceleration due to elevated heat provided by the curing process. The SS/NS ratio of 1 to 2.5 was found to be sufficient to provide for a geopolymeric reaction to take place in the mixture, with $\mathrm{NaOH}$ concentrations of 6-10 M. The optimum result was found at $8 \mathrm{M}$. This result is in agreement with previous geopolymer research done on PCC fly ash [21]. The SS/NS of 0.5 was insufficient to provide enough silicate required for the reaction, while the SS/NS of 3 was possibly beyond the required silicate content. Although the reaction is faster, the higher ratio of $\mathrm{SS} / \mathrm{NS}$ increases the cost in making the geopolymer concrete.

\section{Workability}

The workability of the mortar mixture was tested using the flow table test with the flow diameter measured after 25 knocks on the flow table test. Sufficient workability of the geopolymer mortar needs to be ensured to produce a dense specimen. Therefore, the geopolymer mixture was designed based on the normal consistency of the CFBC fly ash to avoid the need for additives such as superplasticizer.

Figure 4 shows the flow diameter of the geopolymer mortar mixtures for all alkaline activator variations for NA fly ash. All the variations were mixed with relative ease, showing good workability. The mixture with SS/NS of 0.5 showed a lower flow diameter due to the lower content of sodium silicate and lower viscosity of the mixture, however, the mixture still can be cast comfortably.

Workability of the mixture is highly influenced by the normal consistency of the fly ash. When the same mixture composition was applied on the NB fly ash, the composition was too dry for a workable mix. Hence, the water to binder ratio needed to be increased. The normal consistency test is a good indication on the water requirement of the fly ash for sufficient workability.

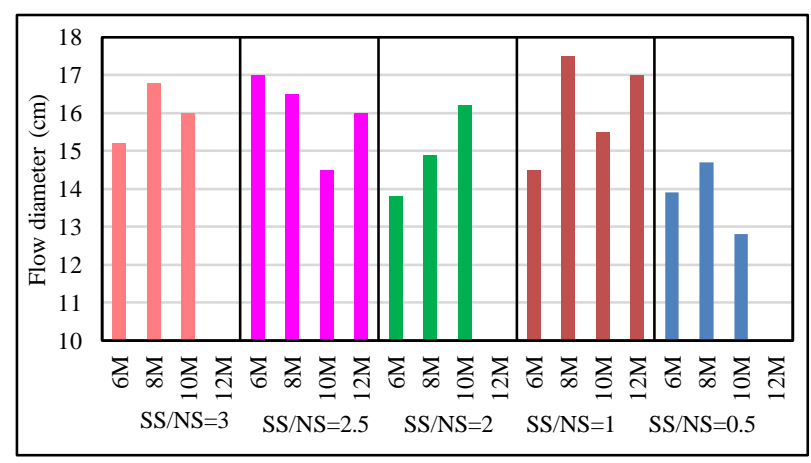

Figure 4. Workability of the Mortar Mixture Measured using the Flow Table Test for NA Fly Ash.

\section{Compressive Strength}

The compressive strength results of the geopolymer mortar at 7, 28, and 90 days for NA fly ash are shown in Figure 5. All geopolymer mortar specimens were cured at $60^{\circ} \mathrm{C}$ for 24 hours to accelerate the geopolymer reaction. Lower strength was obtained for SS/NS of 1 and very low strength was obtained for the mixture using SS/NS of 0.5. These results show that the compressive strength is directly controlled by the alkaline activator ratio, where a lower SS/NS ratio cannot provide enough silicate to ensure a complete geopolymer reaction. 
Variation of the $\mathrm{NaOH}$ concentration seemed so have a lower influence on the strength as long as the concentration was kept at 6-10 M, with higher strength shown at $8 \mathrm{M}$. The day seven strength was highest for the $8 \mathrm{M} \mathrm{NaOH}$ with SS/NS of 2.5 and 3, showing the optimum concentration. The use of very high $\mathrm{NaOH}$ concentration, such as $12 \mathrm{M}$, should be avoided.

The day seven strength values increased due to the acceleration of the oven-cured condition while the 28and 90-day values show the reactivity of the fly ash at room temperature. The result shows that the CFBC fly ash still has some internal reaction under room conditions as opposed to low-calcium PCC fly ash that exhibits almost no increase in the compressive strength in the later age [1].

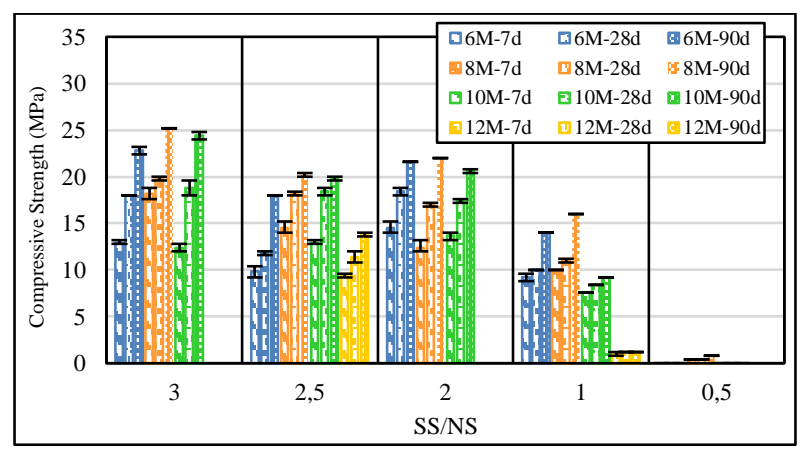

Figure 5. Compressive Strength of the Geopolymer Mortar for NA Fly Ash.

Fly ash NB was made into mortar specimens to compare the variation of the sampling period. The geopolymer composition mixtures were SS/NS of 2.5 and 1 with $\mathrm{NaOH}$ of $6 \mathrm{M}, 8 \mathrm{M}, 10 \mathrm{M}$, and $12 \mathrm{M}$. The compressive strength test was conducted at 7 and 90 days. The water to binder ratio was increased to 0.55 according to a normal consistency test of the fly ash. The compressive strength test results are shown in Figure 6.

The highest compressive strength of $33.4 \mathrm{MPa}$ at 90 days was achieved in a geopolymer mortar mixture with $\mathrm{SS} / \mathrm{NS}$ of 2.5 and $8 \mathrm{M} \mathrm{NaOH}$. The SS/NS ratio of 1 showed a lower strength, indicating a lack of silicate in the mixture. The increase in strength with time was similar to the fly ash NA, achieving similar final strength after 90 days.

Although the free water to binder ratio of the NB fly ash is higher than the NA fly ash $(0.55-0.375)$ the compressive strength of the NB fly ash is still higher; this phenomenon needs to be studied further with more fly ash variation because mixtures with a lower water to binder ratio typically result in higher compressive strength.

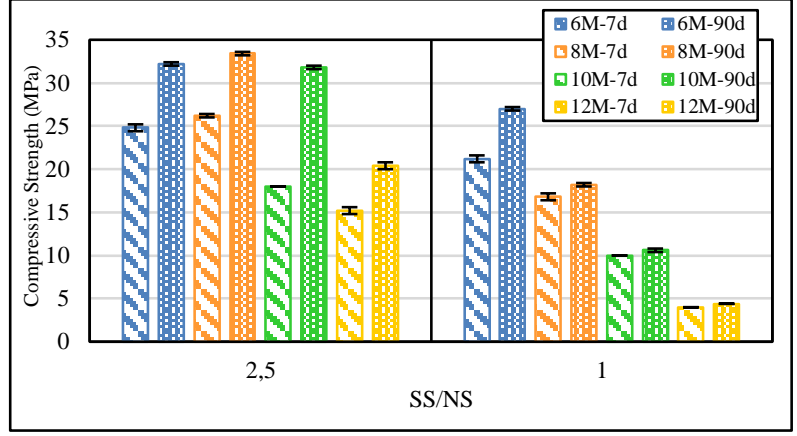

Figure 6. Compressive Strength of the Geopolymer Mortar for NB Fly Ash.

\section{Visual Observation}

Visual observation was conducted on NA fly ash for all alkaline activator variations prepared. The physical appearance of geopolymer mortar at room temperature and after 28 days of $1 \mathrm{~cm}$ water immersion is illustrated in Figure 7. The glossy finishing in the geopolymer surface was due to the use of plastic molding without any contaminant. The glossiness of the geopolymer matrix is highly influenced by the ratio of sodium silicate and sodium hydroxide solution (SS/NS), with a higher ratio producing a gloss finish. The $\mathrm{SS} / \mathrm{NS}=0.5$ was shown to produce a dull surface with a dusty feel when touched, indicating a lack of sodium silicate in its mixture.

As illustrated in Figure 7, no efflorescence was observed for any of the geopolymer mortar mixes even after being soaked in water. Slight hazing was observed for mixtures with $6 \mathrm{M} \mathrm{NaOH}$. However, there was no deposit of loose crystals on the surface to suggest efflorescence.

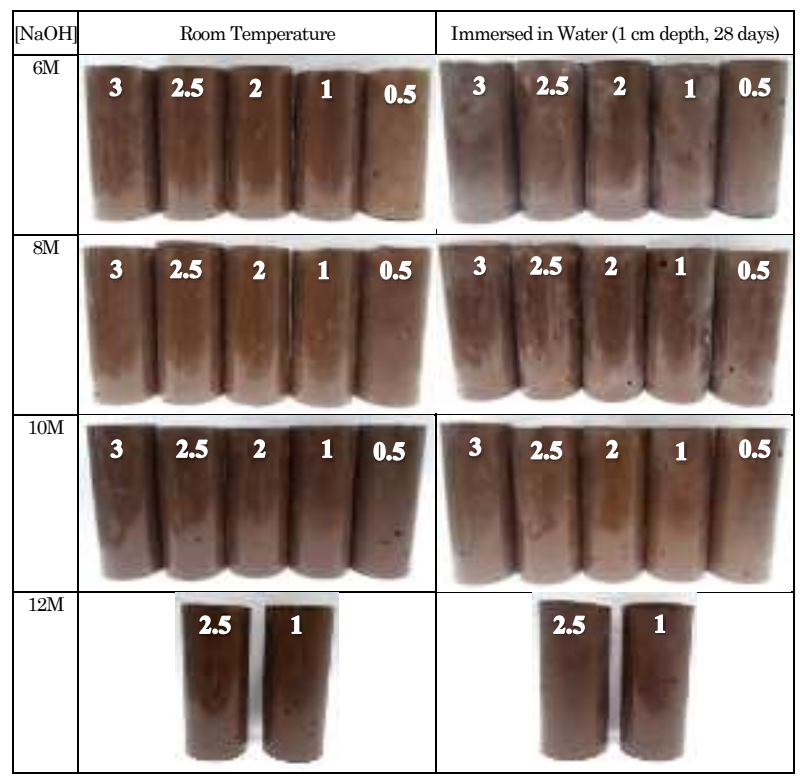

Figure 7. Photographs of Visually Inspected Specimens to Check the Stability of the Geopolymer Mixtures after 28 Days of $1 \mathrm{~cm}$ Water Immersion 


\section{Conclusions}

Low-sulfur CFBC fly ash has been used as a precursor in making geopolymer mortar. This study yields the following conclusions:

1. Low-sulfur CFBC fly ash can be used as a precursor in making geopolymer mortars with strict control in its workability due to the higher normal consistency of the fly ash, which results in higher free water demand in the mixture.

2. The optimum $\mathrm{NaOH}$ solution concentration is $8 \mathrm{M}$ with a ratio of sodium silicate to sodium hydroxide solution of 2.5. This alkaline activator composition resulted in compressive strength of 25.2 $\mathrm{MPa}$ for NA fly ash and 33.4 MPa for NB fly ash at 90 days.

3. Fly ash taken from the CFBC burner could have a significant variation in its chemical and physical properties between sampling periods for which the water to binder ratio and the alkaline activator composition need to be adjusted accordingly.

4. Visual observation of efflorescence and compressive strength tests on the mortar specimens indicate the stability of the geopolymer reaction.

\section{References}

1. Hardjito, D., Wallah, S.E., Sumajouw, D.M.J., and Rangan, B.V., On the Development of Fly Ash-Based Geopolymer Concrete, ACI Material Journal,101, 2004, pp. 467-72

2. The National Coal Council, Coal: America's Energy Future, Washington DC: The National Coal Council, 2006.

3. Basu, P. and Fraser, S.A., Circulating Fluidized Bed Boilers, Springer, 1991.

4. Chi, M., Huang, R., Wu, T., and Fou, T., Utilization of Circulating Fluidized Bed Combustion (CFBC) Fly Ash and Coal-fired Fly Ash in Portland Cement, Key Engineering Materials, 629-630, 2015, pp. 306-13

5. Robl, T., Mahboub, K., Stevens, W., and Rathbone, R., Fluidized Bed Combustion Ash Utilization: CFBC Fly Ash as a Pozzolanic Fluidized Bed Combustion Ash Utilization : CFBC Fly Ash as a Pozzolanic Additive to Portland Cement Concrete, Second International Conference on Sustainable Construction Materials and Technology, Ancona, Italy, June 28-30, 2010.

6. Wang, C., Jia, L., Tan, Y., and Anthony, E.J., Carbonation of Fly Ash in Oxy-fuel CFB Combustion, Fuel, 87(7), 2008, pp. 1108-1114.

7. Chindaprasirt, P., Rattanasak, U., and Jaturapitakkul, C., Utilization of Fly Ash Blends from Pulverized Coal and Fluidized Bed Combustions in Geopolymeric Materials, Cement and Concrete Composite, 33(1), 2011, pp. 55-60.

8. Shi, G.C., Xiao, J.L., Qun, Y.W, Lu, J.T., and Ya, J.W., Influence of Alkali Activator Dosage on
Strength of CFBC Fly Ash Based Geopolymer, 2017 World of Coal Ash (WOCA) Conference, Lexington, USA, 2017.

9. Donthuam, P., Sawangwong, P., and Pachana, P., Effect of Fluidized Bed Coal Combustion Fly Ash on Geopolymer's Properties, IOSR Journal of Environmental Science, Toxicology and Food Technology, 10(4), 2016, pp. 91-96.

10. Hardjito, D., Rangan, B.V., Wallah, S.E., and Sumajouw, D.M., Studies on Fly Ash-Based Geopolymer Concrete, Curtin University, Perth, Australia, 2005.

11. Antoni, Wijaya, S.W., and Hardjito, D., Compressive Strength of Geopolymer based on the Fly Ash Variation, Material Science Forum, 841, 2016, pp. 98-103.

12. Zhang, Z.H., Yang, T., and Wang, H., The effect of Efflorescence on the Mechanical Properties of Fly Ash-based Geopolymer Binders, 23rd Australasian Conference on the Mechanics of Structures and Materials (ACMSM23), vol I, 2014, pp. 107-112.

13. Zhang, Z., Wang, H., Provis, J.L., and Reid, A., Efflorescence: A Critical Challenge for Geopolymer Applications?, Concrete Institute of Australia's Biennial National Conference, 2013, pp. $1-10$.

14. ASTM C187 2016, Standard Test Method for Amount of Water Required for Normal Consistency of Hydraulic Cement Paste, West Conshohocken, PA, 2016.

15. ASTM C191 2018, Standard Test Method for Time of Setting of Hydraulic Cement by Vicat Needle, ASTM International, West Conshohocken, PA, 2018.

16. ASTM C 1437-07 2009, Standard Test Method for Flow of Hydraulic Cement Mortar, Annual B, ASTM Standard 6-7, 2009.

17. ASTM D5239 2012, Standard Practice for Characterizing Fly Ash for Use in Soil Stabilization, ASTM International, West Conshohocken, PA, 2012.

18. Salain, I.M.A.K., Study on Reactivity of Circulating Fluidized Bed Combustion Fly Ashes in the Presence of Water, Civil Engineering Dimension, 12(1), 2010, pp. 29-35.

19. Li, F., Zhai, J., Fu, X., and Sheng, G., Characterization of Fly Ashes from Circulating Fluidized Bed Combustion (CFBC) Boilers Cofiring Coal and Petroleum Coke, Energy and Fuels, 20(4), 2006, pp. 1411-1417.

20. [Silva, L.F.O., Oliviera, M. L. S., Kautzmann, R.M., Ramox, C.G., Izquierdo, M., Dai, S., Wilcox, J., Hoffman, J., and Hower, J.C., Geochemistry and Mineralogy of Coal-Fired Circulating Fluidized Bed Combustion Fly Ashes, Coal Combustion and Gasification Products, 6(2), 2014. 
21. Antoni, Wibiatma, S.W., and Hardjito, D., Factors Affecting the Setting Time of Fly Ashbased Geopolymer, Materials Science Forum, 841, 2016, pp. 90-97.
22. Lăzărescu, A.V., Szilagyi, H., Baeră, C., and Ioani, A., The Effect of Alkaline Activator Ratio on the Compressive Strength of Fly Ash-Based Geopolymer Paste, IOP Conference Series Materials Science Engineering, 209, 2017, 012064. 